\title{
Aspects on the Catalysis of Lipase from Porcine Pancreas (type VI-s) in Aqueous Media: Development of Ion-pairs
}

\author{
Marina Kokkinou, Leonidas G. Theodorou and Emmanuel M. Papamichael * \\ Sector of Organic Chemistry and Biochemistry; Laboratory of Enzymology; Dept. of Chemistry; University of \\ Ioannina; Ioannina 45110 - GREECE
}

\begin{abstract}
This article reports a first contribution for the elucidation of catalytic mechanism of Lipase from porcine pancreas, type VI-s (PPL), in hydrolyzing an ester substrate in aqueous media. The conclusions were based on the pH-profiles of Michaelis-Menten parameters $k_{c a t} / K_{m}, k_{\text {cat }}$ and $K_{m}$, as well as on the absolute temperature profile of $k_{\text {cat }} / K_{m}$, obtained during the hydrolysis of p-nitrophenyl laurate by PPL. It was found that (a) PPL performs catalysis by means of ion pairs formed either as $\mathrm{Ser}^{152}-\mathrm{O}^{-} / \mathrm{His}^{263}-\mathrm{Im}^{+} \mathrm{H}$ and/or Carbonyl-O $/ \mathrm{His}^{263}-\mathrm{Im}^{+} \mathrm{H}$, (b) the parameter $k_{\text {cat }} / K_{m}$ equals to $k_{l}$ and thus ES is formed and destroyed in the course of a series of consecutive reactions governed by the dynamic constant $K_{S}=k_{2} / k_{1}$, and (c) the hydrolysis of substrate is assisted by a hydrogen bond developed between deprotonated Asp ${ }^{176}$ and the positively charged imidazole of $\mathrm{His}^{263}$ across a pK $\mathrm{K}_{a}$-value 3.85, necessary for efficient catalysis.
\end{abstract}

Key words: Porcine Pancreas Lipase, mechanism of hydrolysis, p-nitrophenyl laurate

\section{INTRODUCTION}

Lipases or triacylglycerol acylhydrolases (E.C. 3.1.1.3) catalyze the hydrolysis of various chainlength fatty acids esters and form diacylglyceride or monoacylglyceride, and/or glycerol and free fatty acids. These enzymes have found a variety of industrial applications due to their catalytic properties on a wide spectrum of substrates, as well as due to their high stability towards extreme temperatures and $\mathrm{pH}$-values of the reaction media (Verger 1997; Thomson et al. 1999). The kinetics and mechanisms of lipolysis have been studied to some extend to improve the applications of lipases, as controlled lipolysis is essential for the consistent quality of commercial products (Salleh et al. 2006). The catalytic site of lipases comprises three residues (Asp or Glu, His, Ser) in a straightforward similarity to serine proteases
(Derewenda and Sharp, 1993). Generally, the minimum reaction Scheme 1 appears insufficient and ambiguous to explain how Lipase from porcine pancreas type VI-s (PPL) performs catalysis (Jaeger and Eggert, 1994); thus, it seems reasonable to study the catalytic mechanism of PPL.

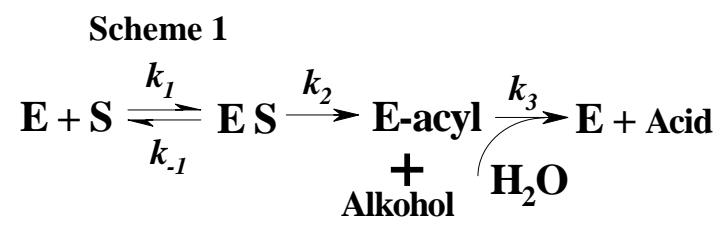

This manuscript reports a first contribution for the elucidation of catalytic mechanism of the PPL in hydrolyzing the synthetic ester substrate $\mathrm{CH}_{3}\left(\mathrm{CH}_{2}\right)_{10} \mathrm{C}(=\mathrm{O})$-ONP (p-nitrophenyl laurate - L$\mathrm{p}$-ONP) in aqueous buffers of $0.01 \mathrm{M}$ ionic

\footnotetext{
*Author for correspondence: epapamic@cc.uoi.gr
} 
strength, containing $0.15 \%(\mathrm{w} / \mathrm{v})$ Arabic gum and $5 \%(\mathrm{v} / \mathrm{v})$ DMSO. For this reason, we analyzed the dependencies of Michaelis-Menten parameters in the hydrolysis of L-p-ONP by PPL as functions of $\mathrm{pH}$-value and/or of $k_{\text {cal }} / K_{m}$ versus absolute temperature, of the reaction means. We found that catalysis is performed by means of ion pairs formed either as $\mathrm{Ser}^{152}-\mathrm{O}^{-} / \mathrm{His}^{263}-\mathrm{Im}^{+} \mathrm{H}$ and/or Carbonyl-O $/ \mathrm{His}^{263}-\mathrm{Im}^{+} \mathrm{H}$, whereas $k_{\text {cal }} / K_{m}$ is almost equal to $k_{l}$; furthermore, the hydrolysis of the substrate is assisted by a hydrogen bond developed between $\mathrm{Asp}^{176}$ and the positively charged imidazole of $\mathrm{His}^{263}$ (lipase numbering), across a $\mathrm{p} K_{\mathrm{a}}$-value 3.85 , necessary for efficient catalysis (Theodorou et al. 2007a; 2007b).

\section{MATERIALS AND METHODS}

Lipase from porcine pancreas type VI-s (PPL), pnitrophenyl laurate (L-p-ONP), Arabic gum, 2mercaptoethanol, dimethylsulfoxide (DMSO) and other chemical were purchased from Sigma.

The $\mathrm{pH}$ value of the stock phosphate buffers was checked on a radiometer $\mathrm{pH}$-meter model PHM 82. Suitable $\mathrm{pH}$ and temperature activity measurements were carried out in aqueous $0.01 \mathrm{M}$ buffers containing $2 \mathrm{mM}$ 2-mercaptoethanol; same buffers were employed for active site titrations achieved by using the irreversible inhibitor PMSF. The working solutions of the substrate were prepared in DMSO (Theodorou et al, 2007a; 2007b).

All kinetic measurements were performed spectrophotometrically by initial velocities at 405 $\mathrm{nm}$ for the L-p-ONP substrate, in a Specord 205 UV-VIS spectrophotometer; aqueous lipase solutions, of about $3930 \mathrm{nM}$, were prepared containing $5 \mathrm{gr} / 100 \mathrm{ml}$ Arabic gum. In a typical kinetic run a test-tube was prepared, containing the appropriate quantities of buffer and enzyme solutions, and DMSO at a final total content of 5\% $(\mathrm{v} / \mathrm{v})$; next, a reference-tube was prepared where Arabic gum solution had replaced the enzyme solution. Then, both tubes are placed in an ultrasonic bath for $5 \mathrm{~min}$ at the appropriate temperature and the reaction is initiated by the addition of 10-50 $\mu \mathrm{l}$ of substrate solution (in DMSO) in both test and reference tubes. The substrate concentration varied from $10 \mu \mathrm{M}$ to 200 $\mu \mathrm{M}$. Again, both tubes are placed in the ultrasonic bath for $15 \mathrm{~min}$; then $1 \mathrm{ml} \mathrm{NaOH} 0.1 \mathrm{M}$ is added in both tubes and the absorbance of test tube was measured versus the reference one at $405 \mathrm{~nm}$ due to the release of p-nitro-phenyl anion<smiles>[O]c1ccc([N+](=O)[O-])cc1</smiles>

Additional, measurements were performed in the range $5.50 \leq \mathrm{pH} \leq 10.50$, in buffers of $0.01 \mathrm{M}$ ionic strength prepared as previously (Theodorou et al. 2007a; 2007b), in order to obtain appropriate $\mathrm{pH}-(k)$ profiles. Similar measurements were performed at different temperatures ranging from $13^{\circ} \mathrm{C}$ to $65^{\circ} \mathrm{C}$ in phosphate buffers of $0.01 \mathrm{M}$ ionic strength at pH 6.50 (Papamichael et al. 2009).

All parameters were estimated from initial velocities measurements, during the hydrolysis of L-p-ONP substrate by PPL, using nonlinear curve fitting of the appropriate equation to the experimental data. In more details, the experimental data of the dependencies of $k_{c a t} / K_{m}$ $k_{\text {cat }}$ and $K_{m}$ versus $\mathrm{pH}$ were best analyzed according to Schemes 2, 3 and 4, and best fitted by different simplified forms of equation (1) comprising three to five hydrogenic forms but only one operative reactive state (Topham et al. 1991). The experimental data of the dependency of $k_{c a t} / K_{m}$ versus temperature were best fitted by equation (2), where $k_{1,0}, a_{0}, E_{1}$ and $E_{a}=E_{-l}-E_{2}$, represent the values of: rate constant $k_{1}$, the ratio $k_{2} / k_{-1}$, the activation energies corresponding to the rate constants $k_{1}, k_{-1}$ and $k_{2}$, at the reference temperature $\mathrm{T}_{0}=318.15^{\circ} \mathrm{K}\left(45^{\circ} \mathrm{C}\right) ; \mathrm{T}$ and $\mathrm{R}$ are the independent variable (temperature in ${ }^{\circ} \mathrm{K}$ ) and the gas constant $\left(8.3144 \mathrm{Jmol}^{-1} \mathrm{~K}^{-1}\right)$, respectively (Theodorou et al. 2007a; 2007b; Valasaki et al, 2008; Papamichael et al. 2009; 2010; Papamichael and Theodorou, 2010).

\section{Scheme 2}

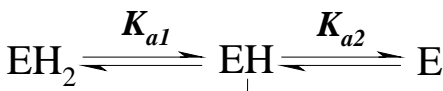

$$
\begin{aligned}
& \boldsymbol{k}_{c a t} / \boldsymbol{K}_{\boldsymbol{m}} \text { or } \boldsymbol{k}_{c a t} \\
& \text { Towards Next Step }
\end{aligned}
$$

\section{Scheme 3}

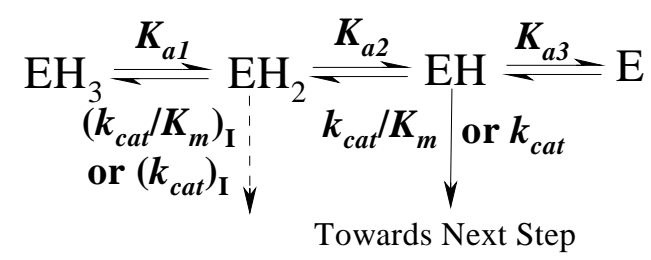




\section{Scheme 4}

$$
\begin{aligned}
& \mathbf{E H}_{4} \stackrel{K_{a 1}}{=} \mathbf{E H}_{3} \stackrel{K_{a 2}}{=} \mathrm{EH}_{2} \stackrel{K_{a 3}}{=} \mathrm{EH} \stackrel{K_{a 4}}{=} \mathrm{E} \\
& \begin{array}{l|l|l}
\left(\boldsymbol{k}_{c a t} / \boldsymbol{K}_{\boldsymbol{m}}\right)_{\mathbf{I I}}\left(\boldsymbol{k}_{c a l} / \boldsymbol{K}_{\boldsymbol{m}}\right)_{\mathbf{I}} & \boldsymbol{k}_{c a t} / \boldsymbol{K}_{\boldsymbol{m}}
\end{array} \\
& \text { or }\left(k_{\text {cat }}\right)_{\text {II }} \text { or }\left(k_{\text {cat }}\right)_{\text {I }} \quad \downarrow \text { or } k_{\text {cat }} \\
& \text { Towards Next Step } \\
& (\boldsymbol{k})_{\mathrm{obs}}=\sum_{\mathrm{i}=1}^{\mathrm{n}} \frac{(\boldsymbol{k})_{\mathrm{XH}_{\mathrm{i}-1}}^{\lim _{\mathrm{j}=1}}}{\left(1+\sum_{\mathrm{i}, \mathrm{j}}^{\mathrm{n}} \mathrm{B}_{\mathrm{j}}\right)}
\end{aligned}
$$

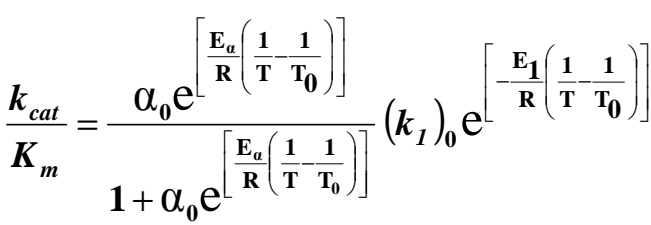

Alternative fitting procedures of all series of the above mentioned experimental data were performed also by non-parametric curve fitting methods, and/or by suitable reparametrization of all used simplified forms of equations (1) and (2), until become linear in their parameters, as it has been described previously (Theodorou et al. 2001; Papamichael et al. 2000; Papamichael and Theodorou 2009). In most cases, global minima were approached, and reached to the same results.

\section{RESULTS}

The experimental data from the $\mathrm{pH}-\left(k_{c a l} / K_{m}\right)$ profile are best fitted by equation $\left(k_{c a l} / K_{m}\right)_{o b s}=$ $\left(k_{c a l} / K_{m}\right)^{l i m} /\left(1+10^{\mathrm{p} K_{a 1^{+}}+\mathrm{p} K_{a 2^{2}}+\mathrm{pK}_{a 3^{3}}-\mathrm{p \textrm {H }}}+10^{\mathrm{p} K_{a 2^{2}} K_{a 3^{-}}}\right.$ $2 \mathrm{pH}+10^{\mathrm{p} K_{a 3}-\mathrm{pH}}+10^{\mathrm{pH}-\mathrm{p} K_{a 4}}$

4; the experimental data from the $\mathrm{pH}-\left(k_{c}\right)$ and $\mathrm{pH}-\left(K_{m}\right)$ profiles are best fitted by equations $\left(k_{c a t}\right)_{o b s}=\left(k_{c a t}\right)^{l i m} /\left(1+10^{\mathrm{p} K_{a l}+\mathrm{p}_{a 2^{-2}} \mathrm{pH}}+10^{\mathrm{pK}}{ }_{a 2^{-} \mathrm{pH}}+10^{\mathrm{pH}-}\right.$ $\left.{ }^{\mathrm{p} K_{a 3}}\right)$ and $\left(K_{m}\right)_{o b s}=\left(K_{m}\right)^{l i m} /\left(1+10^{\mathrm{p} K_{a l^{-2}} \mathrm{pH}}+10^{\mathrm{pH}-\mathrm{p} K_{a 2}}\right)$, corresponding to Scheme 3 and 2, respectively.

All pH-profiles were found as bell-shaped showing maxima at almost neutral $\mathrm{pH}$-values in all

\begin{tabular}{|c|c|}
\hline Michaelis-Menten Parameter & $\mathrm{p} K_{a}$-values \\
\hline & $\mathrm{p} K_{a l}=2.21 \pm\left(2.20 \times 10^{-7}\right)$ \\
\hline$\left(k_{c o v} / K_{m}\right)^{\lim }=1424440.43$ & $\mathrm{p} K_{\rho}=3.86 \pm\left(1.38 \times 10^{-10}\right)$ \\
\hline$\pm\left(9.42 \times 10^{-8}\right)\left(\mathrm{M}^{-1} \mathrm{~s}^{-1}\right)$ & $\mathrm{p} K_{a 3}=5.68 \pm\left(6.67 \times 10^{-13}\right)$ \\
\hline & $\mathrm{p} K_{a 4}=9.96 \pm\left(1.59 \times 10^{-13}\right)$ \\
\hline$\left(k-l^{\lim }-12550\right.$ & $\mathrm{p} K_{a l}=5.85 \pm(0.01)$ \\
\hline$\pm(0.13)\left(\mathrm{s}^{-1}\right)$ & $\mathrm{p} K_{a 2}=6.12 \pm\left(4.30 \times 10^{-3}\right)$ \\
\hline$\left(K_{m}\right)^{\lim }=8.18 \times 10^{-2}$ & $\begin{array}{l}\left.\mathrm{p} K_{a 3}=9.23 \pm 2.00 \times 10^{-3}\right) \\
\mathrm{n} K\end{array}$ \\
\hline$\pm(0.01)(\mathrm{mM})$ & $\mathrm{p} K_{o}=9.60 \pm(0.27)$ \\
\hline
\end{tabular}
cases of Michaelis-Menten parameters (Fig. 1); the $\mathrm{p} K_{a}$-values were estimated with small standard deviations, and are depicted in Table 1.

Table 1 - The estimated parameters from the dependencies of $k_{c a t} / K_{m}, k_{c a}$ and $K_{m}$ versus pH.
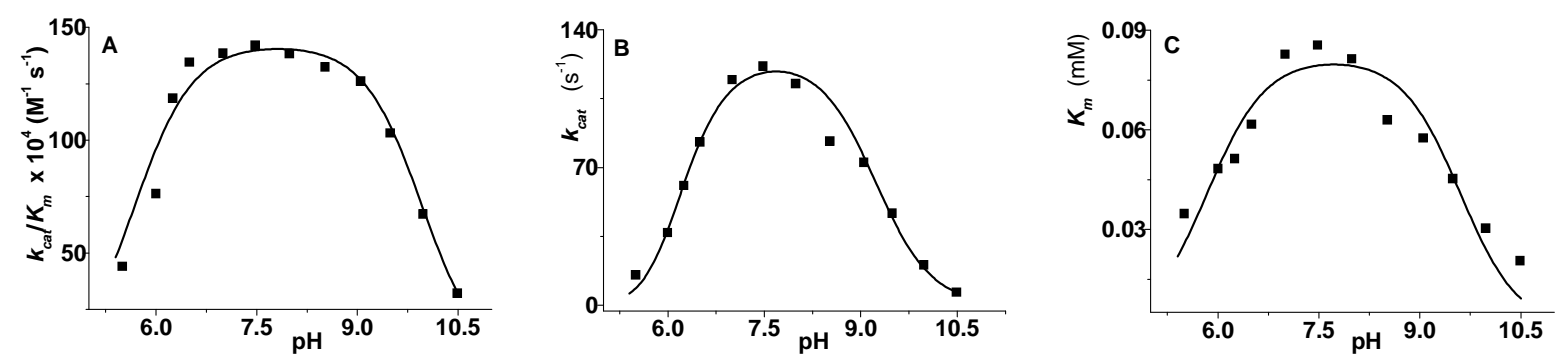

Figure 1 - (A) the $\mathrm{pH}-\left(k_{c a t} / K_{m}\right),(\mathrm{B})$ the $\mathrm{pH}-\left(k_{c a t}\right)$ and $(\mathrm{C})$ the $\mathrm{pH}-\left(K_{m}\right)$ profiles of the hydrolysis of Lp-ONP substrate by PPL. The experimental data are best fitted according to Schemes 4, 3 , and 2 and the corresponding equations, respectively. 
In the case of absolute Temperature- $\left(k_{c a l} / K_{m}\right)$ profile, the experimental data were best fitted by equation (2), and the following parameter values were estimated (Fig. 2):

(a) $k_{1,0}=1344643.56 \pm 4.50 \times 10^{-6} \mathrm{M}^{-1} \mathrm{~s}^{-1}$, which corresponds to the rate constant $\boldsymbol{k}_{1}$ at $45^{\circ} \mathrm{C}$,

(b) $a_{0}=k_{2} / k_{-1}=21.30 \pm\left(9.80 \times 10^{-10}\right)$,

(c) $E_{a}=214477.17 \pm\left(2.50 \times 10^{-6}\right) \mathrm{kJ} / \mathrm{mol}$, and

(d) $E_{I}=4315.38 \pm\left(1.4 \times 10^{-7}\right) \mathrm{kJ} / \mathrm{mol}$.

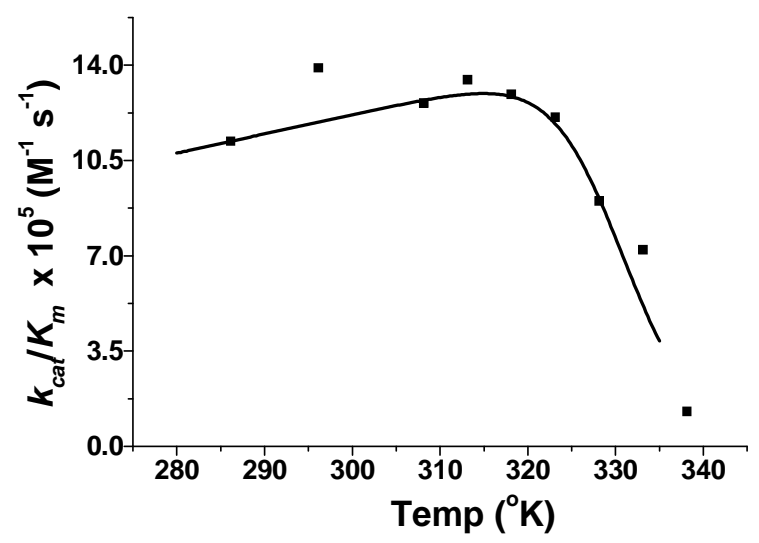

Figure 2 - The dependency of $k_{c a t} / K_{m}$ versus the absolute temperature in the hydrolysis of L-p-ONP substrate by PPL.

\section{DISCUSSION}

The $\mathrm{pH}$-profiles obtained during the hydrolysis of L-p-ONP by PPL reflect the ionization corresponding to each single Michaelis-Menten parameter, which maintains enzyme active conformation and/or is directly involved in catalysis (Benjamin and Pandey 2000; Rajendran et al. 2009). Similarly, from the absolute temperature- $\left(k_{c a t} / K_{m}\right)$ profile were obtained useful relations. However, we should emphasize that both $\mathrm{pH}$ and absolute temperature profiles were achieved by performing kinetic measurements in aqueous media of relatively low ionic strength containing 5\% $(\mathrm{v} / \mathrm{v})$ DMSO and $0.15 \%\left({ }^{\mathrm{w}} / \mathrm{v}\right)$ Arabic gum, whose usefulness in assays of lipase has been well documented (Mentez and Castro 2005; Salleh et al. 2006).

In all cases, the $\mathrm{p} K_{a}$-values were estimated with small standard errors. The $\mathrm{pH}-\left(k_{c a t} / K_{m}\right)$ profile is affected by three ionizable groups in the acidic and one in the basic limb. A value of $\mathrm{p} K_{a l}=2.21$ could be due to the protonic dissociation of $\mathrm{Asp}^{176}$. Likewise, it seems more likely that a catalytic ionpair $\left(\mathrm{Ser}^{152}-\mathrm{O}^{-} / \mathrm{Hin}^{263}-\mathrm{Im}^{+} \mathrm{H}\right)$ is formed across a $\mathrm{p} K_{a 3}=5.68$, while it breaks across a $\mathrm{p} K_{a 4}=9.96$. Furthermore, an estimate of $\mathrm{p} K_{\mathrm{a} 2}=3.86$ seems reasonable to be due to the development of a hydrogen bond connecting deprotonated $\mathrm{Asp}^{176}$ and positively charged $\mathrm{His}^{263}$. In fact, a reasonable explanation for the development of such a hydrogen bond may be based on the fact that the anion $\mathrm{Ser}^{152}-\mathrm{O}^{-}$(PPL numbering) should be free of hydrogen bonds in order to become more nucleophilic when it is attacking on the substrate (Theodorou et al. 2007a; 2007b; Papamichael et al. 2009; 2010; Papamichael and Theodorou, 2010). The best fit of the experimental data of $\mathrm{pH}-\left(k_{c a t}\right)$ and/or $\mathrm{pH}-\left(K_{m}\right)$ profiles gave evidence for the estimation of three and/or two $\mathrm{p} K_{a}$-values, respectively. In these latter cases, it seems more likely that a different ion-pair is formed by means of the carbonyl oxygen of the acyl-group, and the positively charged $\mathrm{His}^{263}$ (Carbonyl-O-O/His ${ }^{263}$ $\operatorname{Im}^{+} \mathrm{H}$ ), across almost identical estimates of $\mathrm{p} K_{a 1}=$ 5.85 and/or 5.84 respectively. This second ion-pair breaks across a $\mathrm{p} K_{a}$-value 9.60 i.e. the mean value between $\mathrm{p} K_{a 4}=9.96, \mathrm{p} K_{a 3}=9.23$ and $\mathrm{p} K_{a 2}=9.60$, estimated from the $\mathrm{pH}-\left(k_{c a t} / K_{m}\right), \mathrm{pH}-\left(k_{c a t}\right)$ and $\mathrm{pH}-$ $\left(K_{m}\right)$ profiles, respectively, which differ only less than 4\% (Papamichael et al. 2004; Theodorou et al. 2007a; 2007b; Papamichael and Theodorou, 2010). Finally, an estimated $\mathrm{p} K_{a 2}=6.12$ could denote the protonation of the $\mathrm{N}^{\square 2}$-atom of $\mathrm{His}^{263}$ as a $\mathrm{H}_{2} \mathrm{O}$ molecule is attacking the acyl-enzyme (Theodorou et al. 2001, 2007a, 2007b; Papamichael et al. 2004, 2009). 
From the absolute temperature- $\left(k_{c a t} / K_{m}\right)$ profile the ratio $\alpha_{0}=k_{2} / k_{-1}=21.30$ was obtained, denoting the relation $k_{2} \gg k_{-l}$ and thus $k_{c a l} / K_{m} \approx k_{l}$; similarly, the estimated values of activation energies $E_{a}$ and $E_{1}$ are in full agreement to the obtained results from the $\mathrm{pH}$ profiles of the Michaelis-Menten parameters. Moreover, the relation $K_{S}=\left(k_{2}+k\right.$. $\left.{ }_{1}\right) / k_{1}=k_{2} / k_{1}$ is valid as $k_{2}>>k_{-l}$. On the basis of all mentioned above, it could be concluded that the ES complex is formed and destroyed in the course of a series of consecutive reactions governed by a dynamic constant, the so-called $K_{S}$, established according to: $\mathbf{E}+\mathbf{S} \stackrel{\boldsymbol{k}_{1}}{\longrightarrow}$ E S $\stackrel{\boldsymbol{k}_{2}}{\longrightarrow}$ E-acyl.
Additionally, it is not unexpected that under the experimental conditions of the present work it was found that PPL hydrolyses p-nitrophenyl laurate (L-p-ONP) by means of general acid-base catalysis (ionic pairs), and not through a chargerelay-system, as it is the case in serine proteases having similar catalytic site with lipases. Accordingly, a first contribution in the elucidation of the catalytic mechanism of PPL in hydrolyzing the synthetic ester substrate L-p-ONP in aqueous media could be depicted by the below Scheme 5 .

\section{Scheme 5}

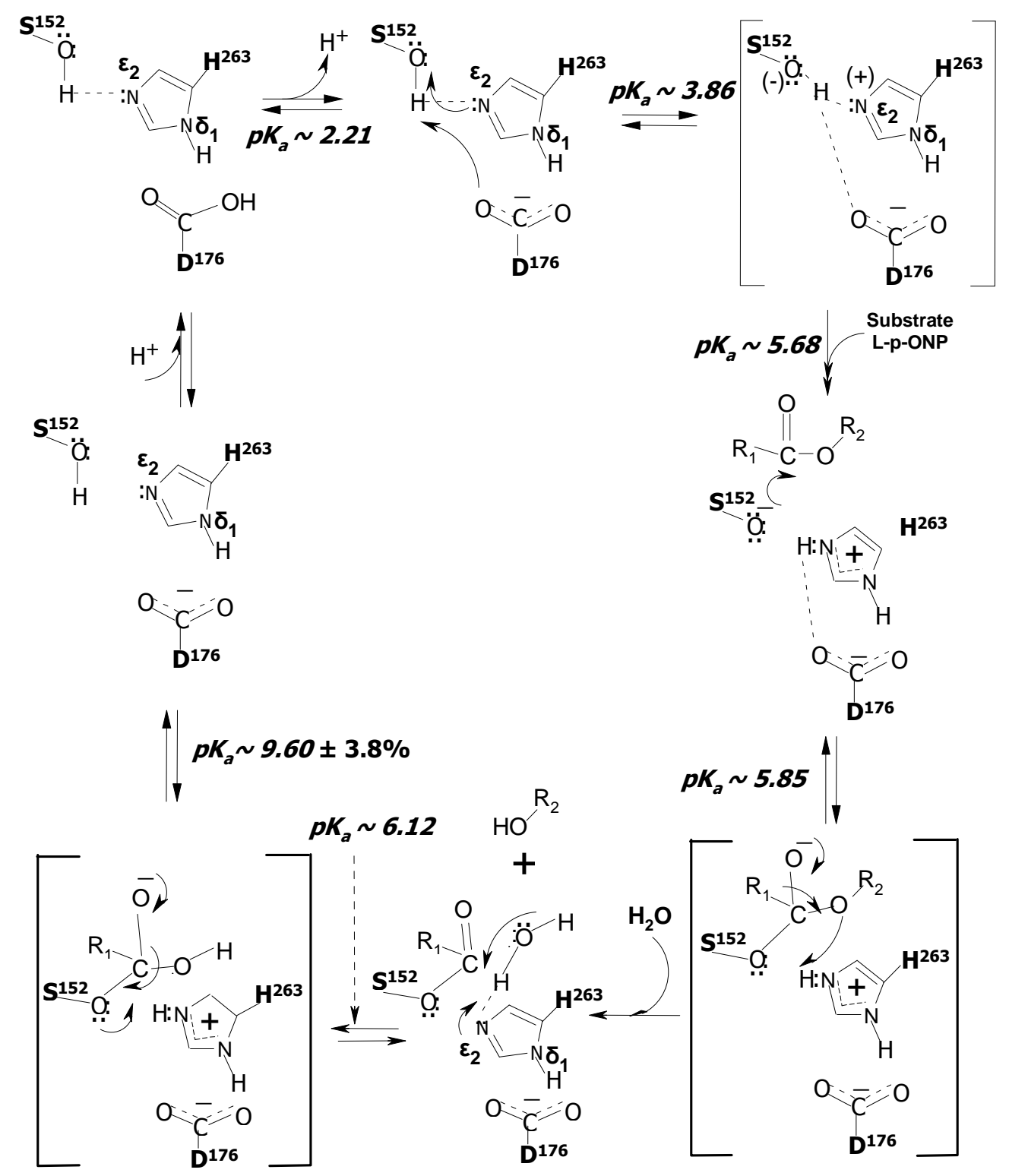




\section{REFERENCES}

Benjamin S, Pandey A. Isolation and Characterization of Three Distinct Forms of Lipases from Candida rugosa Produced in Solid State Fermentation, Braz Arch Biol Technol. 2000; 43: 453-460.

Derewenda ZS, Sharp AM. News from the interface: the molecular structures of triacyglyceride lipases. Trends in Biochemical Sciences. 1993; 18: 20-25.

Jaeger KE, Eggert T. Lipases for biotechnology. Current Opinion In Biotechnology. 2002; 13: 390397.

Mentez AA, de Castro HF. Effect on the Enzymatic Hydrolysis of Lipids from Dairy Wastewater by Replacing Gum Arabic Emulsifier for Sodium Chloride, Braz Arch Biol Technol. 2005; 48: 135-145.

Papamichael EM, Evmiridis NP, Potosis C. Nonparametric Fitting of Nonlinear Equations to Experimental Data without Use of Initial Guessing: A Basic Computer Program. Braz. Arch. Biol. Technol. 2000; 43: 1-9.

Papamichael EM, Theodorou LG, Bieth JG. Insight Into Catalytic Mechanism of Papain-Like Cysteine Proteinases: the case of $\mathrm{D}^{158}$. Applied Biochemistry and Biotechnology-Part A Enzyme Engineering \& Biotechnology. 2004; 118: 171-175.

Papamichael EM, Theodorou LG. Necessary Auxiliary Background for Efficient Use of an Existing Computer Program of Non-parametric Fitting of Nonlinear Equations. Braz Arch Biol Technol. 2009; 52: 437-448.

Papamichael EM, Bieth JG, Theodorou LG, Lymperopoulos K, Valasaki K. The elucidation of the mechanism of action of cysteine proteinases of the Papain-C1 family: possible biotechnological applications, in New Horizons in Biotechnology, Eds: Pandey A., Larroche C.,m Soccol C-R., \& Dussap CG., Asiatech Publishers, INC. New Delhi, India, 2009. p. 104-122.

Papamichael EM, Theodorou LG. Experimental and theoretical approaches in investigating enzymatic mechanisms: Applications on the thermo-stable extracellular Protease-A-17N-1 from Bacillus sp., with possible biotechnological interest, in Current Topics on Bioprocesses in Food Industry Vol III, Eds: Rao LV, Pandey A, Larroche C, Soccol CR, \& Dussap CG. Asiatech Publishers, INC. New Delhi, India. 2010; p. 130-139.

Papamichael EM, Theodorou LG, Perisynakis A, Drainas C. Purification and Characterization of a novel extracellular protease from a halo-alkalophilic Bacillus sp. $17 \mathrm{~N}-1$, active in polar organic solvents. Environmental Technology (Special Issue: Extremophiles). 2010; 31: 1073-1082.
Rajendran A, Palanisamy A, Thangavelu V. Lipase Catalyzed Ester Synthesis for Food Processing Industries. Braz Arch Biol Technol. 2009; 52: 207219.

Salleh AB, Rahman R, Basri M. New Lipases and Proteases. Eds. Salleh A.B., Rahman RNZRA \& Basri M., in Nova Science Publishers, Inc. New York; 2006. p. 1-22.

Theodorou LG, Lymperopoulos K, Bieth JG, Papamichael EM. Insight into the Catalysis of Hydrolysis of four Newly Synthesized Substrates by Papain: A Proton Inventory Study. Biochemistry-US. 2001; 40: 3996-4004.

Theodorou LG, Bieth JG, Papamichael EM. The catalytic mode of cysteine proteinases of papain $(\mathrm{C} 1)$ family. Bioresource Technology. 2007a; 98: 19311939.

Theodorou LG, Perisynakis A, Valasaki K, Drainas C, and Papamichael EM. Proton Inventories Constitute Reliable Tools in Investigating Enzymatic Mechanisms: Application on a Novel Thermo-stable Extracellular Protease from a Halo-Alkalophilic Bacillus sp. J. Biochem. 2007b; 142: 293-300.

Thomson CA, Delaquis PJ, Mazza G, Detection and measurement of microbial lipase activity. Crit Rew Food Sci Nutrit. 1999; 39: 165-187.

Topham CM, Salih E, Frazao C, Kowlessur D, Overington JP, Thomas M, Brocklehurst SM, Patel M, Thomas EW, Brocklehurst K. Structure-function relationships in the cysteine proteinases actinidin, papain and papaya proteinase. Three-dimensional structure of papaya proteinase omega deduced by knowledge-based modelling and active-centre characteristics determined by two-hydronic-state reactivity probe kinetics and kinetics of catalysis. Biochem. J. 1991; 280: 79-92.

Valasaki K, Staikou A, Theodorou LG, Charamopoulou V, Zacharaki P, Papamichael EM. Purification and kinetics of two novel thermophilic extracellular proteases from Lactobacillus helveticus, from kefir with possible biotechnological interest. Bioresource Technology. 2008; 99: 5804-5813.

Verger R. Interfacial activation of lipases: Facts and artifacts. Trends in Biotechnology. 1997; 15: 32-38.

Received: July 15, 2011; Revised: November 27, 2011; Accepted: February 15, 2012. 